\title{
Bisfosfonatbehandling av osteoporose og andre skjelettsykdommer
}

\author{
Sammendrag \\ Bakgrunn. Bisfosfonater er antiresorp- \\ tive medikamenter som er i utstrakt \\ bruk i behandling av osteoporose. De \\ benyttes også ved flere medfødte bein- \\ sykdommer med systemiske eller \\ lokale defekter samt som ledd \\ $i$ behandlingen av kreft. Vi gir her en \\ oversikt over farmakokinetikk, virk- \\ ningsmekanismer og kliniske effekter.
}

Materiale og metode. Artikkelen er basert på et ikke-systematisk litteratursøk i PubMed.

Resultater. Bisfosfonater er derivater av pyrofosfat som binder seg med en sterk affinitet til hydroksyapatitt. Aminobisfosfonatene hemmer et enzym i mevalonatsynteseveien, noe som fører til hemming av osteoklastaktiviteten og apoptose av osteoklasten. Det er dokumentert redusert insidens av vertebrale frakturer og hoftebrudd etter behandling med alendronat, risedronat og zoledronat, mens det for ibandronat bare er vist reduksjon av vertebrale brudd. Hos pasienter som nylig hadde hatt hoftebrudd og ble behandlet med zoledronat, ble det også observert lavere mortalitet. Intravenøse bisfosfonater sikrer etterlevelsen (compliance) og er relativt enkle å bruke. Bisfosfonatbehandling reduserer risikoen for skjelettkomplikasjoner og beinsmerter ved brystkreft, myelomatose og prostatakreft. De er også effektive i behandling av Pagets sykdom og beinmargs$ø$ dem. Gastrointestinale bivirkninger er relativt hyppig ved bruk av perorale bisfosfonater, mens akuttfasereaksjoner med et influensaliknende bilde er vanlig ved intravenøs behandling.

Fortolkning. Aminobisfosfonatene er effektive i behandling av osteoporose og andre beinsykdommer og som adjuvans $\mathrm{i}$ behandling av kreft.

\section{Unni Syversen}

unni.syversen@ntnu.no

Avdeling for endokrinologi

St. Olavs hospital

7006 Trondheim

og

Institutt for kreftforskning og molekylær medisin Norges teknisk-naturvitenskapelige universitet

\section{Johan I. Halse}

Osteoporoseklinikken

Pilestredet Park 12

Oslo

De antiresorptive bisfosfonatene har i løpet av de siste 15 årene fått en stor plass i osteoporosebehandlingen $(1,2)$. Ett problem ved peroral bisfosfonatbehandling er at den ikke gjennomføres som foreskrevet eller avsluttes etter kort tid (3). Nylig er intravenøse bisfosfonater for behandling av osteoporose blitt tilgjengelig. Bisfosfonater benyttes også ved flere medfødte beinsykdommer og i behandling av kreft. Formålet med denne artikkelen er å oppsummere de senere års kunnskaper på feltet.

\section{Materiale og metode}

Vi utførte et ikke-systematisk PubMed-søk og valgte ut oversiktsartikler og metaanalyser på grunnlag av vår erfaring som klinikere og forskere innen fagfeltet osteoporose.

\section{Biokjemi}

Bisfosfonater er derivater av pyrofosfat hvor oksygenatomet mellom fosforatomene er byttet ut med et karbonatom, som vist i figur 1. Strukturen til de to sidekjedene bundet til karbonatomet er bestemmende for den biologiske aktiviteten. Den ene sidekjeden er avgjørende for substansens antiresorptive egenskaper. Aminobisfosfonater har en nitrogenforbindelse i sidekjeden, noe som øker det antiresorptive potensialet $\mathrm{i}$ forhold til bisfosfonater uten nitrogenforbindelse. Den andre sidekjeden er ansvarlig for bisfosfonatets affinitet til beinsubstansen. Bindingen til beinvev er av betydning for langtidseffektene av de ulike bisfosfonatene og er i avtakende rekkefølge sterkest for zoledronat, alendronat, ibandronat og risedronat og svakest for etidronat (4).

\section{Farmakokinetikk}

Opptaket av bisfosfonater i tarmen er svært lavt $(<1 \%)$, og inntak av mat eller drikke (unntatt vann) innen 30 minutter etter tablettinntak reduserer opptaket ytterligere. Av- hengig av affiniteten bindes fra $20 \%$ (etidronat) til $80 \%$ (alendronat) av opptatt mengde bisfosfonat til beinvevet. Bindingene mellom karbon og fosfor spaltes ikke. Bisfosfonatandelen i serum skilles derfor ut gjennom nyrene i uendret tilstand. Halveringstiden varierer mellom 30 minutter og to timer på grunn av ulik binding til albumin. Intravenøse bisfosfonater har lengre eliminasjonstid på grunn av større grad av binding til proteiner og danning av aggregater.

Aminobisfosfonater binder seg hovedsakelig til områder hvor det foregår aktiv beinresorpsjon. Ukentlig administrering av alendronat $o g$ risedronat og månedlig dosering av ibandronat gir tilsvarende økning i beintetthet som daglig dosering. Intravenøse preparater gis enten hver tredje måned (ibandronat) eller en gang per år (zoledronat) i behandling av osteoporose. Ved kreft kan intervallet mellom injeksjonene være betydelig kortere.

\section{Virkningsmekanisme}

Aminobisfosfonater tas opp av osteoklastene og hemmer enzymet farnesylpyrofosfatsyntetase, et nøkkelenzym i mevalonatmetabolismen $(5,6)$. Dette medfører manglende prenylering av små signalproteiner (Rho, Ras), noe som resulterer i nedsatt funksjonsevne av osteoklastene og apoptose $(5,6)$.

Bisfosfonater uten aminogruppe bidrar til danning av en cytotoksisk ATP-analog som induserer apoptose av osteoklasten. Denne egenskapen har også aminobisfosfonatene, men den har sannsynligvis mindre betydning for effekten av disse preparatene.

Hemming av osteoklastaktivitet og apoptose fører til redusert beinomsetning. I løpet av dager til uker kan man påvise reduksjon i

\section{Hovedbudskap}

- Bisfosfonater er antiresorptive medikamenter som reduserer risikoen for osteoporotiske frakturer i både rygg og hofte

- Perorale bisfosfonater er førstevalg i behandling av osteoporose

- Etterlevelse er et problem med perorale bisfosfonater

- Bisfosfonater til intravenøs bruk er et alternativ ved gastrointestinale bivirkninger eller der det er problemer med etterlevelsen 
markører for osteoklastaktivitet, noe senere også reduksjon i markører for osteoblastaktivitet. Dette innebærer at resorpsjonskaviteter i beinvevet fylles. Som følge av økt sekundær mineralisering blir det en økning i beintetthet uten vesentlig økning i beinvolumet. Det er også beskrevet positive effekter på osteoblaster og osteocytter (7).

\section{Behandling av osteoporose}

Store studier av høy kvalitet viser at alendronat, risedronat og ibandronat forebygger vertebrale frakturer hos postmenopausale kvinner med osteoporose (tab 1) (8-14). I disse studiene ble pasientene utvalgt på grunnlag av beintetthetsmålinger med påvisning av osteoporose i hofte eller lumbalcolumna med eller uten vertebral fraktur. For alendronat og risedronat er det også vist redusert risiko av hoftefrakturer og andre perifere brudd $(9,15)$. I en studie med risedronat der pasientene ble inkludert på grunnlag av alder og kliniske risikofaktorer, ikke på bakgrunn av beintetthetsmåling, var det ikke reduksjon i hoftefrakturrisko i behandlingsgruppen sammenliknet med placebogruppen (15). Det er uvisst hvor stor andel av disse pasientene som hadde osteoporose, da det ikke ble foretatt beintettsmåling.

Studier med alendronat og risedronat der deltakerne var menn med osteoporose og pasienter med glukokortikoidindusert osteoporose viser gunstig effekt på beintetthet og redusert bruddrisiko (16-18).

Ibandronat og zoledronat gitt intravenøst er nylig tatt $\mathrm{i}$ bruk $\mathrm{i}$ behandling av osteoporose. Intravenøst ibandronat har tilsvarende effekt på beintetthet og beinmarkører som peroralt ibandronat gitt daglig, men det er ikke gjort studier med henblikk på fraktur (19).

Zoledronat $5 \mathrm{mg}$ som infusjon over $15 \mathrm{mi}$ nutter en gang årlig i tre år har vært testet i en placebokontrollert studie med 7765 postmenopausale kvinner med osteoporose (14). Insidensen av morfometriske vertebrale frakturer etter tre år var 10,9 \% (310 kvinner) i placebogruppen versus 3,3\% (92 kvinner) i zoledronatgruppen, en reduksjon på $70 \%$ (RR 0,30; $95 \%$ KI 0,24-0,38). Insidensen av<smiles>O=P(O)(O)OP(=O)(O)O</smiles>

Pyrofosfat<smiles>[R]C([R])(P(=O)(O)O)P(=O)(O)O</smiles>

Bisfosfonat

Figur 1 Generisk struktur av pyrofosfat og bisfosfonat med funksjonelle domener

hoftebrudd var $2,5 \%$ (88 kvinner) i placebogruppen og 1,4\% (52 kvinner) i zoledronatgruppen, en reduksjon på $41 \%$ (hasardratio $0,59 ; 95 \% \mathrm{KI} 0,42-0,83)$. Andelen ikke-vertebrale frakturer, alle kliniske frakturer og kliniske vertebrale frakturer var signifikant redusert i zoledronatgruppen (henholdvis $25 \%$, $33 \%$ og $77 \%$ ) (20). Deltakerne i intervensjonsgruppen tapte mindre høyde og hadde færre dager med ryggsmerter.

I en studie hvor pasientene ble inkludert på bakgrunn av at de nylig hadde hatt en hoftefraktur, fant man også reduksjon av alle typer brudd ved behandling med zoledronat (20). Ut fra beintetthetsmåling i hofte foretatt ved inklusjon hadde $41,8 \%$ osteoporose. Det var også $28 \%$ lavere mortalitet i behandlingsgruppen $(9,6 \%$ versus $13,3 \%$ døde). Median oppfølgingstid i studien var 1,9 år.

Det er usikkert om det er vesentlige forskjeller i frakturforebyggende effekt mellom de ulike bisfosfonatene. En sammenliknende studie mellom alendronat og risedronat viste større økning av beintettheten i alendronatgruppen, men ingen forskjell i frakturforekomst (21). De gode resultatene ved intravenøs zoledronatbehandling kan være en konsekvens av høy etterlevelse (compliance) eller en spesifikk zoledronateffekt. En over- siktsartikkel hvor 14 studier av perorale bisfosfonater ble gjennomgått, viste at $18-78 \%$ av pasientene fortsatt brukte medisinen etter et år (22). Resultatene var noe bedre ved ukentlig enn ved daglig dosering. En reseptregisterstudie av perorale bifosfonater viste at etterlevelsesrater på over $75 \%$ ga betydelige større risikoreduksjon for alle typer frakturer enn lavere grad av etterlevelse - og at effekten avtok suksessivt (23).

I klinisk praksis starter man med perorale bisfosfonater og skifter eventuelt til intravenøse hvis pasienten får plagsomme gastrointestinale bivirkninger. Intravenøse bisfosfonater skal ikke gis ved hypokalsemi eller nedsatt nyrefunksjon (GFR $>35 \mathrm{ml} / \mathrm{min}$ ).

\section{Andre indikasjoner}

Bisfosfonater benyttes ved flere medfødte beinsykdommer der det er systemiske eller lokale defekter, og det er påvist betydelig økning $\mathrm{i}$ beintettheten hos både barn og voksne. Charcots fot ved diabetes mellitus er en form for beinnekrose som påvirkes gunstig av bisfosfonatbehandling (24). Smertefulle stressfrakturer og en beslektet, meget smertefull tilstand, lokalisert osteoporose med beinmargsødem, har også vært vellykket behandlet med bisfosfonat intravenøst $(25,26)$. En

Tabell 1 Ulike aminobisfosfonaters effekt på insidensen av vertebrale frakturer. Studier av tre års varighet med fraktur som endepunkt. Omarbeidet og gjengitt med tillatelse fra Clinical Interventions in Aging (8)

Medikamentstudier

(totalt antall deltakere)

Alendronat $(\mathbf{1 0} \mathbf{~ m g )}$

FIT VFA (2 027)

FIT CFA (4 432) 4 år

Risedronat (5 mg)

VERT-NA (2 458)

VERT-MN (1 226)

Ibandronat (2,5 $\mathbf{m g}$ )

BONE (2 946)

Zoledronat

HORIZON-PFT (7 765)
Forfattere

Frakturinsidens (\%)

Placebo

Aktiv

Behandlingseffekt

P-verdi

RR (95\% KI)

Black og medarbeidere 1996 (9)

15,0

8,0

$0,53(0,41-0,68)$

$<0,001$

Cummings og medarbeidere 1998 (10)

3,8

2,1

$0,56(0,39-0,80)$

0,002

Harris og medarbeidere 1999 (11)

16,3

11,3

$0,59(0,42-0,82)$

0,003

29,0

18,1

$0,51(0,36-0,73)$

$<0,001$

Chesnut og medarbeidere 2004 (13)

9,6

4,7

$0,38(0,25,0,59)$

0,0001

Black og medarbeidere 2007 (14)

10,9

3,3

$0,30(0,24,0,38)$ 
zoledronatinfusjon gir en langvarig remisjon ved Pagets sykdom, og øvrige aminobisfosfonater er også effektive (27).

Bisfosfonatbehandling reduserer risikoen for skjelettkomplikasjoner, gir mindre beinsmerter og er effektiv behandling av hyperkalsemi i forbindelse med brystkreft, myelomatose og prostatakreft (28-31). Ved disse tilstandene gis bisfosfonater hyppigere (hver 3.-4. uke), dermed blir totaldosen større enn ved behandling av osteoporose. Aminobisfosfonater påvirker mevalonatmetabolismen i kreftceller og bidrar til apoptose. Det er nylig vist at zoledronat (4 mg hver sjette måned i tre år) i kombinasjon med endokrin terapi (tamoksifen eller anastrozol) hos premenopausale kvinner med østrogenreseptorpositiv brystkreft i tidlig stadium førte til redusert risiko for progrediering sammenliknet med endokrin terapi alene (absolutt reduksjon $3,2 \%$, relativ reduksjon $36 \%$ (hasardratio $0,64 ; 95 \%$ KI $0,46-0,91 ; p=0,01))(32)$.

\section{Bivirkninger}

I studier har bisfosfonater ikke gitt flere bivirkninger enn placebo $(9-13,15)$. I klinisk praksis er imidlertid gastrointestinale bivirkninger relativt vanlig ved peroral behandling og en hovedårsak til seponering. Vanligst er dyspepsi med blødninger og strikturerende øsofagitt, som de alvorligste, men også diaré kan forekomme. Det er usikkert om det er noen forskjell mellom ulike perorale bisfofonater når det gjelder disse bivirkningene. Artralgi, periostsmerte og iridosyklitt er sjeldne bivirkninger som er reversible etter behandlingsstopp.

Intravenøse bisfosfonater gir sjelden gastrointestinale bivirkninger. I løpet av første døgn etter en intravenøs injeksjon opplever ca. $20 \%$ et influensaliknede syndrom med myalgier og feber som varer fra timer til dager. Symptomene avtar etter annen og er sjeldne etter tredje injeksjon. Reaksjonene kan unngås eller svekkes ved bruk av paracetamol eller ibuprofen i 1-2 dager i tilslutning til injeksjonen. Akuttfasereaksjoner er også observert etter de første perorale doser av alendronat $(70 \mathrm{mg})$ og ibandronat $(150 \mathrm{mg})$.

Bisfosfonater er kontraindisert ved alvorlig nyresvikt (GFR $<35 \mathrm{ml} / \mathrm{min}$ ), men perorale preparater har vært benyttet både hos nyretransplanterte og hos pasienter med alvorlig nyresvikt $(33,34)$. Sviktende nyrefunksjon hos kreftpasienter som har fått relativt store doser bisfosfonater intravenøst er rapportert $(35,36)$. Ibandronat er muligens mindre nefrotoksisk enn zoledronat og pamidronat (35). I studiene med ibandronat og zoledronat ved postmenopausal osteoporose fant man ingen endring i gjennomsnittlig nyrefunksjon under tre års behandling $(14,19)$.

I zoledronatstudien med postmenopausale kvinner ble det påvist økt risiko for rask, behandlingskrevende atrieflimmer (14). Årsaken til dette er ukjent, og en slik assosiasjon er ikke vist $i$ andre studier med zoledronat eller perorale aminobisfosfonater (37).
Atypiske lavenergifrakturer av femur er rapportert hos pasienter som har fått langvarig behandling med orale bisfosfonater (34). Den kausale sammenhengen er imidlertid fortsatt under diskusjon.

Mandibulære og maksillære beinnekroser ble rapportert første gang i 2004 i forbindelse med bruk av intravenøst bisfosfonat hos kreftpasienter $(38,39)$. I en oversiktsartikkel ble det konkludert at forekomsten av osteonekrose er lav hos dem som får bisfosfonater for osteoporose eller Pagets sykdom, i størrelsesorden 1 per 100000 pasientår (40). Insidensen av osteonekrose ved kreft er mye høyere $(2-10 \%)$, men er basert på retrospektive undersøkelser av varierende kvalitet. I behandling av kreft med beinmetastaser gis totaldoser av zoledronat som kan være minst ti ganger høyere enn dosene som benyttes ved osteoporose. Muligens er risikoen større ved intravenøs bruk av zoledronat og pamidronat enn ved ibandronat intravenøst. Etiologien og patogenesen til denne alvorlige bivirkningen er fortsatt dårlig kartlagt (41).

Kjevekirurgiske inngrep, inflammasjon, immunsuppresjon med cytostatika eller glukokortikoider synes å være hyppig assosiert med osteonekrose. Det anbefales sanering av munnhuleinfeksjoner og dårlige tenner før oppstart av høydose intravenøs bisfosfonatbehandling av kreftpasienter. For behandling av postmenopausal osteoporose er det ingen spesielle anbefalinger. Pasienten bør informeres om tilstanden og anbefales god tannhygiene og regelmessig tannlegekontroll etter vanlige retningslinjer. I zoledronatstudien ved postmenopausal osteoporose var det ett tilfelle av osteonekrose i placebogruppen og ett $\mathrm{i}$ behandlingsgruppen hvor infeksjon og kjevekirurgi var fellesnevner (14).

Man har nå mer enn ti års klinisk erfaring med perorale bisfosfonater. Dataene tyder på at beinkvaliteten opprettholdes og at frakturrisikoen er mindre. Med unntak av osteonekrose er ingen nye organspesifikke bivirkninger rapportert (42).

\section{Varighet av bisfosfonatbehandling}

Etter fem års alendronatbehandling er det etter seponering et gradvis tap av beintetthet (43), men fem år etter seponeringen er beintettheten fortsatt høyere enn ved behandlingsstart. I samme periode øker den relative risikoen for kliniske vertebrale frakturer sterkere for dem som avslutter etter fem år enn for dem som fortsetter behandlingen. Siden substansen bygges inn i beinvevet, kan man regne med at bisfosfonater har samme halveringstid som dette, dvs. rundt ti år. De forskjellige bisfosfonatene har ulik affinitet til beinvev, og kunnskapen fra studier med alendronat kan ikke umiddelbart overføres til de andre.

Det er ingen nasjonale retningslinjer for hvor lenge behandlingen skal vare, men i praksis kan det kan være aktuelt å avslutte etter fem år hvis beintettheten har økt så mye at frakturrisikoen formodes å være lav. Hvis ikke, tyder dataene med alendronat på at man kan fortsette behandlingen i ytterligere fem år uten stor risiko for organspesifikke bivirkninger.

\section{Kostnadseffektivitet}

I studiene har det vært ulike inklusjonskriterier, og kostnadseffektiviteten varierer derfor sterkt. Vertebrale frakturer er ofte ikke tatt med i beregningene. Like fullt er behandling med aminobisfosfonater funnet å være kostnadseffektivt i flere situasjoner (44-46). Siden frakturforekomsten i Norge er 2-3 ganger høyere enn den er i ikke-skandinaviske land, er det sannsynlig at gevinsten underestimeres i beregninger fra andre land (47). Innføring av generisk alendronat har ført til betydelig bedre kostnadseffektivitet.

I dag gis alendronat på blåresept dersom det foreligger lavenergibrudd og osteoporose. Etter prisreduksjonen bør det vurderes om refusjonsgrunnlaget kan utvides til osteoporose uten fraktur. Effektiviteten av alendronat ved primærprofylakse er nylig dokumentert (48).

Oppgitte interessekonflikter: Johan I. Halse har mottatt honorar for fordragsvirksomhet og/eller bidrag til kongressreiser fra følgende firmaer: Roche, GSK, MSD, Pfizer, Eli Lilly, Nycomed, Aventis, Novartis, Roche, GSK og MSD. Aventis og Novartis markedsfører bisfosfonatpreparater i Norge. Unni Syversen har fått reisestøtte og honorar for faglige foredrag fra Eli Lilly, MSD, Novartis og Nycomed og har deltatt i multisenterstudier for utprøvning av zoledronat (Novartis) i behandling av osteoporose.

\section{Litteratur}

Aaseth J, Syversen U. Førre $\emptyset$. Difosfonater - farmakologi og klinisk bruk. Tidsskr Nor Lægeforen 1998; 118: 1064-6.

2. Syversen U, Halse JI. Behandling av osteoporose. Tidsskr Nor Lægeforen 2003; 123: 2263-4.

3. Carr AJ, Thompson PW, Cooper C. Factors associated with adherence and persistence to bisphosphonate therapy in osteoporosis: a cross-sectiona survey. Osteoporos Int 2006; 17: 1638-44.

4. Nancollas GH, Tang R, Phipps RJ et al. Novel insights into actions of bisphosphonates on bone: differences in interactions with hydroxyapatite. Bone 2006; 38: 617-27.

5. Kavanagh KL, Guo K, Dunford JE et al. The molecular mechanism of nitrogen-containing bisphosphonates as antiosteoporosis drugs. Proc Natl Acad Sci U S A 2006; 103: 7829-34

6. Russell RGG, Watts NB, Ebetino FH et al. Mechan isms of action of bisphosphonates: similarities and differences and their potential influence on clinical efficacy. Osteoporos Int 2008; 19: 733-59.

7. Plotkin LI, Manolagas SC, Bellido T. Dissociation of the pro-apoptotic effects of bisphosphonates on osteoclasts from their anti-apoptotic effects on osteoblasts/osteocytes with novel analogs. Bone 2006; 39: 443-52

8. Bock O. Felsenberg D. Bisphosphonates in the management of postmenopausal osteoporosis-optimizing efficacy in clinical practice. Clin Interv Aging 2008; 3: 279-97.

9. Black DM, Cummings SR, Karpf DB et al; Fracture Intervention Trial Research Group. Randomised trial of effect of alendronate on risk of fracture in women with existing vertebral fractures. Lancet 1996; 348: 1535-41.

10. Cummings SR, Black DM, Thompson DE et al. Effect of alendronate on risk of fracture in women with low bone density but without vertebral fractures: results from the Fracture Intervention Trial. JAMA 1998; 280: 2077-82 
11. Harris ST, Watts NB, Genant HK et al; Vertebral Efficacy With Risedronate Therapy (VERT) Study Group. Effects of risedronate treatment on vertebral and nonvertebral fractures in women with postmenopausal osteoporosis: a randomized controlled trial. JAMA 1999; 282: 1344-52.

12. Reginster J, Minne HW, Sorensen $\mathrm{OH}$ et al; Vertebral Efficacy with Risedronate Therapy (VERT) Study Group. Randomized trial of the effects of risedronate on vertebral fractures in women with established postmenopausal osteoporosis. Osteoporos Int 2000; 11: 83-91.

13. Chesnut CH III, Skag A, Christiansen C et al; Oral Ibandronate Osteoporosis Vertebral Fracture Trial in North America and Europe (BONE). Effects of oral ibandronate administered daily or intermittently on fracture risk in postmenopausal osteoporosis. J Bone Miner Res 2004: 19: 1241 -9.

14. Black DM, Delmas PD, Eastell R et al. Once-yearly zoledonic acid for treatment of postmenopausal osteoporosis. N Engl J Med 2007; 356: 1809-22.

15. McClung MR, Geusens P, Miller PD et al. Effect of risedronate on the risk of hip fracture in elderly women. Hip Intervention Program Study Group. N Engl J Med 2001; 344: 333-40.

16. Orwoll E, Ettinger M, Weiss S, Miller P et al. Alendronate for the treatment of osteoporosis in men N Engl J Med 2000. N Engl J Med 343: 604-610.

17. Ringe JD, Faber H, Farahmand P et al. Efficacy of risedronate in men with primary and secondary osteoporosis: results of a 1-year study. Rheumatol Int 2006; 26: 427-31.

18. Saag KG, Emkey R, Schnitzer TJ et al; Glucocorticoid-Induced Osteoporosis Intervention Study Group. Alendronate for the prevention and treatment of glucocorticoid-induced osteoporosis. N Engl J Med 1998; 339: 292-9.

19. Delmas PD, Adami S, Strugala $C$ et al. Intravenous ibandronate injections in postmenopausal women with osteoporosis: one-year results from the dosing intravenous administration study. Arthritis Rheum 2006; 54: 1838-46.

20. Lyles KW, Colón-Emeric CS, Magaziner JS et al. The Horizon recurrent fracture trial. Zoledronic acid and clinical fracture and mortality after hip fracture. N Engl J Med 2007; 357: nihpa40967.

21. Reid DM, Hosking D, Kendler D et al. Alendronic acid produces greater effects than risedronic acid on bone density and turnover in postmenopausal women with osteoporosis : results of FACTS international. Clin Drug Investig 2006; 26: 63-74.

22. Cramer JA, Gold DT, Silverman SL et al. A systematic review of persistence and compliance with bisphosphonates for osteoporosis. Osteoporos Int 2007; 18: 1023-31

23. Siris ES, Harris ST, Rosen CJ et al. Adherence to bisphosphonate therapy and fracture rates in osteoporotic women: relationship to vertebral and nonvertebral fractures from 2 US claims databases. Mayo Clin Proc 2006; 81: 1013-22.

24. Jude EB, Selby PL, Burgess J et al. Bisphosphonates in the treatment of Charcot neuroarthropathy: a double blind randomised controlled trial. Diabetologia $2001 ; 44: 2032-7$.

25. Stewart GW, Brunet ME, Manning MR et al. Treatment of stress fractures in athletes with intravenous pamidronate. Clin J Sport Med 2005; 15: 92-4.

26. Ringe JD, Dorst A, Faber H. Effective and rapid treatment of painful localized transient osteoporosis (bone marrow edema) with intravenous ibandronate. Osteoporos Int 2005; 16: 2063-8.

27. Siris ES, Lyles KW, Singer FR et al. Medical management of Paget's disease of bone: indications for treatment and review of current therapies. J Bone Miner Res 2006; 21 (suppl 2): P94-8.

28. Pavlakis N, Schmidt R, Stockler M. Bisphosphonates for breast cancer. Cochrane Database Syst Rev 2005; nr. 3: CD003474.

29. Lacy MQ, Dispenzieri A, Gertz MA et al. Mayo clinic consensus statement for the use of bisphosphonates in multiple myeloma. Mayo Clin Proc 2006; 81: 1047-53.

30. Yuen KK, Shelley M, Sze WM et al. Bisphosphonates for advanced prostate cancer. Cochrane Database Syst Rev 2006; nr. 4: CD006250.

31. Green JR. Bisphosphonates: preclinical review. Oncologist 2004; 9 (suppl 4): 3-13.

32. Gnant M, Mlineritsch B, Schippinger W et al; ABCSG-12 Trial Investigators. Endocrine therapy plus zoledronic acid in premenopausal breast cancer. N Engl J Med 2009; 360: 679-91.
33. Trabulus S, Altiparmak MR, Apaydin S et al. Treatment of renal transplant recipients with low bone mineral density: a randomized prospective trial of alendronate, alfacalcidol, and alendronate combined with alfacalcidol. Transplant Proc 2008; 40: $160-6$.

34. Abrahamsen B. Adverse effects of bisphosphonates. Calcif Tissue Int 2010; 86: 421-35.

35. Bergner R, Diel IJ, Henrich D et al. Differences in nephrotoxicity of intravenous bisphosphonates for the treatment of malignancy-related bone disease. Onkologie 2006; 29: 534-40.

36. Guarneri V, Donati S, Nicolini M et al. Renal safety and efficacy of i.v. bisphosphonates in patients with skeletal metastases treated for up to 10 Years. Oncologist 2005; 10: 842-8.

37. Sørensen HT, Christensen S, Mehnert F et al. Use of bisphosphonates among women and risk of atrial fibrillation and flutter: population based case-control study. BMJ 2008; 336: 813-6.

38. Woo S-B, Hellstein JW, Kalmar JR. Narrative [corrected] review: bisphosphonates and osteonecrosis of the jaws. Ann Intern Med 2006; 144: 753-61.

39. Løkken P. Skoglund LA, Skjelbred P. Kjeveosteonekrose ved bisfosfonatbehandling. Tidsskr Nor Lægeforen 2007; 127: 1945-7.

40. Silverman SL, Landesberg R. Osteonecrosis of the jaw and the role of bisphosphonates: a critical review. Am J Med 2009; 122 (suppl): S33-45.

41. Khosla S, Burr D, Cauley J et al; American Society for Bone and Mineral Research. Bisphosphonateassociated osteonecrosis of the jaw: report of a task force of the American Society for Bone and Mineral Research. J Bone Miner Res 2007; 22: 1479-91.

42. Liberman UA. Long-term safety of bisphosphonate therapy for osteoporosis: a review of the evidence. Drugs Aging 2006; 23: 289-98.

43. Black DM, Schwarts AV, Ensrud KE et al. Effects of continuing or stopping alendronate after 5 years of treatment: the Fracture Intervention Trial Longterm Extension (FLEX): a randomized trial. JAMA 2006; 296: 2927-38

44. Kristiansen IS, Falch JA, Andersen L et al. Bruk av alendronat ved osteoporose - er det kostnadseffektivt? Tidsskr Nor Lægeforen 1997; 117: 2619-22.

45. Stevenson M, Jones ML, De Nigris E et al. A systematic review and economic evaluation of alen dronate, etidronate, risedronate, raloxifene and teriparatide for the prevention and treatment of postmenopausal osteoporosis. Health Technol Assess 2005; 9: 1-160.

46. Ström O, Borgström F, Sen SS et al. Cost-effectiveness of alendronate in the treatment of postmenopausal women in 9 European countries-an economic evaluation based on the fracture intervention trial. Osteoporos Int 2007; 18: 1047-61.

47. Schousboe JT, Ensrud KE, Nyman JA et al. Universal bone densitometry screening combined with alendronate therapy for those diagnosed with osteoporosis is highly cost-effective for elderly women. J Am Geriatr Soc 2005; 53: 1697-704.

48. Wells GA, Cranny A, Peterson J et al. Alendronate for the primary and secondary prevention of osteoporotic fractures in postmenopausal women. Cochrane Syst Rev 2008; nr. 1, CD: 001155.

Manuskriptet ble mottatt 2.4. 2009 og godkjent 23.9. 2010. Medisinsk redaktør Trine B. Haugen. 